\title{
Analysis on Insurance Market Behavior
}

\author{
Xiaoyu Zhang \\ Jianghan University, Wuhan 430023, China \\ 1299378304@qq.com
}

Keywords: insurance; market behavior; classification

\begin{abstract}
The behavior of insurance market is varied. This paper first classifies the behavior of insurance market, then finds out several important behaviors, and discusses the cost and benefit of supervising them, so as to find out the effectiveness of the supervision policy of the main insurance market behavior, and discuss whether there is a space to continue to improve the efficiency of supervision.For the classification of insurance market behavior, this paper intends to divide the insurance market behavior from two angles of behavior subject and behavior nature. The reason why these two angles are classified as the behavior classification standard of insurance market is that the behavior subject of the insurance market is the concrete implementation behavior, the different purpose of the behavior subject determines their behavior trend and the influence on the market. The nature of the market behavior is defined by law and regulated according to law. The regulatory authorities should deal with these acts in accordance with the law.
\end{abstract}

\section{Introduction}

Before discussing the cost and income of insurance market behavior supervision, the author tries to give a more accurate definition of insurance market behavior and define what is the behavior of insurance market. Only by defining the connotation and extension of insurance market behavior can we accurately analyze the cost and income of insurance market behavior supervision and judge the insurance market. Is field behavior monitoring policy effective and whether there is room for further improvement in efficiency?

As the name implies, the insurance market behavior should be the behavior of all insurance market participants in a broad sense, which even includes insurance regulatory authorities. But a broad definition of the behavior of the insurance market is clearly not conducive to our continued analysis of the regulatory policy of the regulatory authorities on market behavior, so here we narrow the scope and define the behavior of the insurance market as participation in the formation, entry into force, and performance of the participants in the process of insurance contracts. It covers all aspects of the insurance market, but generally, the behavior of the insurance market can be classified according to the different standards so as to analyze the content of its supervision according to the behavior of different insurance market.

Market behavior is also an important basis for the supervision of solvency and rate of insurance. 
Only in the standard insurance market, the supervision of solvency and the regulation of the rate are the active water. Therefore, in order to make the solvency as the vane of the safety and stability of the insurer, it is necessary to standardize the market behavior and avoid the misconduct by the market misconduct by the regulatory authorities.

\section{Policyholder's Behavior}

The insured is one of the parties to the insurance contract. The insured and the insurer sign an insurance contract and fulfill their rights and obligations in accordance with the insurance contract. The insured is the buyer of the insurance goods, the consumer of the insurance market, the behavior of the insured has an important influence on the insurance market. At the same time, the insurant is also influenced by the insurance market environment and the other participants in the insurance market, thus deciding the direction of their behavior.

The behavior of the insured in the insurance market is determined by two factors: internal stimuli determined by their own causes and external stimuli caused by external factors. Because of the different age, sex, education level, income level, social class and psychological state, the policy holder has different views on insurance. This leads to a great difference in the type and amount of insurance for the insured. Of course, the insured is most affected by the internal stimulus and the insured needs to be insured. In view of the above, all the internal factors stimulate the insurance demand of the insured. Different insured persons have different degrees of trust in the insurance system, the insurer and the insurance company, which determines the insured tendency and the tendency of insurance. From the above mentioned factors, it is possible to determine the insurance needs of the insured. The factors that they make are mainly focused on the degree of education, the level of income, and the social stratum. Generally speaking, there is a positive correlation between income and educational level and insurance demand, but they are slightly different. The higher education is, the higher the demand for insurance, the higher the demand for insurance, there is no doubt that, however, the impact of income on insurance demand is inverted $U$ distribution, the low income stratum has no economic ability to buy insurance, so the low income class insurance demand is very low almost zero, with the income growth, the demand for insurance is constantly raised. High, however, when the income reached a fairly high level, the demand for insurance began to decline. This is in line with the actual situation of people buying insurance in life, the poorest class and the richest class will not buy insurance, the former is too poor to buy, the latter is too rich and does not want to buy, and the real insurance is a middle-income class.

The external factors that affect the behavior of the insured include social environmental impact (cultural environment, peripheral interpersonal relationship, etc.), and insurance marketing stimulation. These two factors will also affect the market behavior of the insured. The national cultural atmosphere is of great significance to the policyholders. For example, the traditional views of China for thousands of years are "raising children and preventing the old, preventing the famine and preventing the hunger". Naturally, there is a certain resistance to the use of insurance for the aged. In the city, the view that the old life is guaranteed by social insurance and commercial insurance has already been a lot. People accepted, but in the vast rural areas due to the level of economic development and the traditional concept of influence, can not really popular. The insurance marketing stimulus is also an important factor affecting the behavior of the insured. The insurer knows the relevant insurance information through various media ads, and then decides whether to buy insurance according to his own judgment, but this judgment will undoubtedly be greatly affected by the insurance marketing. 


\section{Insurer's Behavior}

The insurer is an important participant in the insurance market. It may even be said that the insurer is an active participant in the insurance market. Compared with the insurer, the insurer is more like a party involved in the passive participation in the insurance market. From the above chart, we can see that many actions of the policyholder are actually a response to the insurer's actions. Insurance marketing will attract the attention of potential policyholders, stimulate their interest in insurance, make them aware of their inherent demand for insurance products, and make a preliminary decision to buy insurance. After that, they are looking for appropriate insurance information. After a series of psychological changes, they will be insured and appropriate. The insurer talks about it and talks about the insurance. Thus it can be seen that the insurer in fact dominates the behavior of the insured, and the final decision made by the insurer about the insured or the non insurance has a great relationship with the insurer.

The dominant position of the insurer's behavior can also be seen from the nature of the insurance contract. The insurance contract is an attached contract, that is to say, the Party of the insurance contract can not put forward its own requirements on the terms of the contract in the process of signing the contract, but can only agree or disagree on the content of the contract put forward by the other party. In this process, the insurer and the applicant have the power to establish the insurance clause. It can only be accepted passively.

On the basis of the initiative of the insurer's behavior, in the insurance market, the supervision of the behavior of the insurer is particularly important. Compared with the insured, the insurer is in an active and advantageous position, and it is easier to make the infringer's behavior rather than the infringement of its rights. Therefore, it is important to regulate the insurers' market behavior and ask them to abide by the law.

\subsection{Insurance Agency}

As with intermediary organizations and agencies in other markets, insurance intermediaries refer to the insurer and the insurer, to assist the insurer to sell the insurance policy, to introduce the policy to the insured and to the insurance policy, to engage in risk management and market assessment, to consult the insurance business and to evaluate and compensate for losses and claims. Insurance intermediaries receive commissions from both parties who sign insurance contracts. Insurance agents, known to the public, have insurance agents. At present, insurance brokers have gradually moved into the field of vision. In addition, there are still unknown insurers. From a broad perspective, actuaries, lawyers and accountants, who provide professional services to the insurance market, can also be regarded as insurance intermediaries.

The direct reason for the emergence of insurance intermediaries is the rapid development of the insurance market in the division of labor and cooperation. Insurance industry can have today's achievements, insurance intermediary work can not be without, insurance intermediary can through their own activities to close the negotiations between the insurance and supply and demand, but also through their own activities to explore the insurance demand, so that the two sides can reduce transaction costs, save time, improve transaction efficiency. In addition, in view of the problem that the insured lacks professional insurance knowledge, the insurance agent can introduce and explain the relevant contents of the insurance contract for its clients to help the clients meet their insurance requirements. And the insurer can also focus on the development of insurance, insurance investment, the construction of insurance information system and so on. The insurance agency can be used to complete the insurance exhibition industry and the related business of the market promotion. 
There is no doubt that the behavior of the insurance market is very diverse, but from its nature, it can be roughly divided into two categories: one is a legal breach of contract and the other is fraud. These two kinds of behaviors have great impact on the insurance market. If the two types of behavior are analyzed in detail, we will find that the generalized breach of contract includes fraud, and fraud is in fact a breach of contract, but the fraud is also more harmful to the development of the insurance industry because of its subjective degree of malignancy. Therefore, the fraud is listed separately.

\subsection{Breach of Contract}

Insurance system is established on the basis of risk sharing, to perform the rights and obligations of the insurance contract as an economic system of execution, insurance contracts occupy a very important position in the insurance. It is a breach of contract that one or two parties of an insurance contract fail to perform the obligations of insurance contract in accordance with the contract after the entry into force of the insurance contract. Fraud, including fraud, is a subjective and malicious breach of contract, and other breach of contract may be due to careless loss or lack of professional knowledge. The breach of this section refers specifically to the latter.

The effect of breach of contract on the insurance market is profound, especially on a large scale of breach of contract. Once the insurance market has such a breach, it is necessary for both the supervisor and the supervisor to review whether there is any defect in the contract. Default is often associated with insurance rates, and as the previous analysis has analyzed, the rate may affect the number and size of the breach.

\subsection{Fraud}

Insurance fraud has a long history, and it can be said to be accompanied by the development of insurance itself. Since the insurance, insurance fraud is like a shadow. To the social production and science and technology highly developed today, insurance fraud is the means to refurbish, various ways. Insurance fraud is an unlawful act of unlawful means to obtain high amount of insurance money by illegal means by using the special nature of the inherent operating mechanism of insurance with maliciously use of insurance. Insurance fraud also exists in both the insured and the insurer. For example, when the applicant is making a contract, the insured deliberately conceals the fact that it is unfavourable to his own party, and obtains an insurance contract by deception; deliberately creates an insurance accident or even desperation to kill a person; deliberately enlarging the scope of the loss to obtain a high amount of compensation from the insurer; fabricate an insurance mark, make up a insurance accident, and make a void. False proof of accident and related proof, etc. And the insurer and the insurance intermediary have the same improper measures in the insurance market behavior. The main improper behavior is that when the insurance contract is signed, the insured can induce the insured to make untrue informs, or know that the insured has uninformed behavior, and the insurance intermediary is in order to reach an insurance transaction. In private, the insured and the insured are given more benefits or disguised rebates, and some insurance intermediaries may conspire with the insured and the insured to jointly cheat the insurer and seek to gain illegal interests.

\section{Summary}

There are many behaviors in the insurance market, including the behavior of the insured, the insurer's behavior and the insurance intermediary behavior. Besides, from the point of view of behavior content, it can also be divided into breach of contract and fraud. These insurance behaviors require supervision by regulators. The content and the basic nature of these behaviors are important 
prerequisites for effective supervision. In particular, breach of contract and fraudulent behavior, as a negative impact of the insurance market behavior, breach of contract and fraud both to the insured or the insurer have great harm, which need the adjustment of insurance regulation. Therefore, the analysis of the classification of the behavior of the insurance market is the next step in the study of the cost and income of insurance supervision. Precondition.

\section{References}

[1] Levin, Neil D. Insurance Supervision Meets the Marketplace: The Regulatory Response to Derivatives as a Risk Management Tool in the Insurance Industry, 69 Fordham L. Rev. 17 (2000-2001).

[2] Lawrence R. Cordell and Kathleen Kuester King, “A Market Evaluation of the Risk-Based Capital Standards for the U.S. Financial System', Journal of Banking and Finance (19) 1995, p. 531-562

[3] Rothchild M., J. Stigliz, Equilibrium in Competitive Insurance Markets: A Essay in the Economics of Imperfect Information, Quarterly Journal of Economics, 88 44-62.

[4] Winter R. A., Solvency regulation and the property-liability "insurance cycle." (1991) Ecoomic Inquiry, vol. 29, issue 3, p.458-471.

[5] Clifford Winston and Robert W. Crandall, “Explaining Regulatory Policy: Brookings Paperson Economic Activity: Microeconomics, 1994, p.1-49. 